\title{
Aftercare for participants in clinical research: ethical considerations in an asthma drug trial
}

\author{
S C Harth and Y H Thong Department of Child Health, University of Queensland, Australia
}

\begin{abstract}
The issue of aftercare for participants in clinical research was explored in the context of an asthma drug trial. Although there may be financial constraints and practical difficulties with implementation, the results show that it may be feasible for clinical investigators and commercial sponsors to take on some limited responsibility for the medical care of research subjects after clinical trials. However, the ethical implications for this practice remain unclear. On the one hand, society may have a moral obligation to compensate and reward some of its members who assume the risk of research subjects for the benefit of society as a whole. On the other hand, the promise of aftercare may provide an inducement to volunteers which, under certain conditions may be considered morally wrong and scientifically unsound.
\end{abstract}

\section{Introduction}

The concept that research subjects deserve to be compensated for research-related injuries was first promulgated in the 1960 s, considered by a number of government agencies in the 1970s, and gained general acceptance in the $1980 \mathrm{~s}$ when it was included in the International Guidelines for Biomedical Research Involving Human Subjects, published by the World Health Organisation and Council for International Organisations of Medical Sciences $(1,2)$. While not yet incorporated into law, there is such a prospect sometime in the 1990s (3). This concept is based on the ethical principle of distributive justice, where society as a whole, which stands to gain from advances in medical knowledge, owes a debt to those of its members who assume increased risks as research subjects to provide the benefits of research to society $(1,3)$.

This concept may be taken one step further to imply some moral obligation on the part of society, sponsors and clinical investigators for the welfare of

\section{Key words}

Human experimentation; aftercare; compensation; research injuries. research subjects after the completion of clinical trials, and indeed, such an extension has been considered by the current European Good Clinical Practice (GCP) guidelines, which state that 'the investigator is medically responsible for those subjects who are under his/her care for the duration of the trial and must ensure that appropriate medical care is maintained after the trial' (4). However, such an extension would be financially prohibitive in the case of subjects with chronic diseases, and the financial burden of providing hospital, medical care and medications for research subjects beyond the duration of the clinical trial would deter even the most affluent of pharmaceutical companies from doing clinical trials for chronic diseases. In this study, we explored the ethical justifications and practical ramifications of this concept in the context of a clinical drug trial for asthma, a chronic disease in children (5-8).

Asthma is a chronic respiratory illness characterised by airway inflammation, resulting in recurrent and reversible airway obstruction. The mainstay of treatment consists of regular administration of bronchodilators (for example, theophylline, betaagonists) and/or anti-inflammatory agents (for example, cromoglycate, corticosteroids). For about half the children diagnosed with asthma, significant symptoms persist into adult life $(9,10)$. This issue of aftercare for children with asthma recruited into our clinical trial of ketotifen (5), a drug as yet unlicensed in Australia, was discussed with our commercial sponsor. The company agreed to provide the drug free-of-charge to all the children under a 'compassionate use' protocol until such time as it became licensed under the Pharmaceutical Benefits Scheme, where it would be either free or subsidised by government, depending on a means test. The question of medical and hospital aftercare for the children was not a major consideration because of universal health cover in Australia. A more relevant question was whether the parents of these children would gain enough information about asthma management during the course of the clinical trial, or whether there would be a need to provide a formal, structured asthma education programme, similar to 
those shown to be effective in reducing morbidity in this disease $(11,12)$. As part of this consideration, we decided to assess the knowledge and attitudes of the parents at the end of the trial to determine the need for providing structured education programmes to these patients.

\section{Methods}

The subjects for the present study were recruited from parents who had volunteered their children for a randomised, double-blind, placebo-controlled trial of ketotifen, a new and unlicensed oral asthma drug (5-8). The subjects were recruited between one to four months after completion of the clinical trial. Of the 46 families in this category available to participate in this study, 43 accepted, giving a participation rate of 91.5 per cent. Comparison families were recruited from children admitted to the same hospital with a definite diagnosis of asthma, but who had not participated in any clinical trial. The children were matched for age and severity of illness. Of 60 families in this group, 55 accepted our invitation to join the study, to give a participation rate of 91.7 per cent.

For the present study we used a 77-item questionnaire, each with five to ten questions which was developed to assess the knowledge, attitudes, compliance and misconceptions about asthma and its treatment (13-16). The parent most involved in the child's asthma management was asked to complete the questionnaire. Detailed sociodemographic information was also obtained. The completed questionnaires were coded and analysed by computer using the SAS statistical package (17).
Fisher's exact test (for $2 \times 2$ tables), and Pearson's Chi-square test were used for statistical analysis. $\frac{\mathrm{m}}{\mathrm{m}}$ Continuous responses were analysed by Students $\underset{ }{ \pm}$. t-test. The level of significance was taken as $p<0.05$.

\section{Results}

\section{SOCIODEMOGRAPHIC CHARACTERISTICS}

There were no significant differences between the $\stackrel{\mathbb{\Omega}}{\Omega}$ two groups of parents in the variables of age, educa- $\cong$ tion, parity, occupation, marital status and ethnic $\vec{P}$ background (data not presented).

\section{PARENTAL KNOWLEDGE AND ATTITUDES ABOUT ASTHMA}

Summary data on parental knowledge and attitudes about asthma are presented in Table 1 . It can be observed that parents who participated in the triali had significantly greater knowledge of the aetiology o of asthma than the comparison group. However,음 their knowledge level was no greater than that of the comparison group for all other aspects of asthma. Participant parents had more negative views abouto the impact of asthma on children, a greater satisfaction with the family doctor, much lower usage of $\vec{\bullet}$ alternative medicine and a more positive attitudece or towards medication than the comparison grous: (Table 1).

\section{Discussion}

Whether or not volunteers for clinical research $\stackrel{\mathbb{D}}{\varrho}$ deserve compensation for research-related injuries $\overrightarrow{\vec{O}}$ and medical care afterwards depends on society's

\section{Table 1}

\section{Summary data on parental knowledge and attitudes about asthma}

Knowledge and attitudes about asthma

\section{Knowledge}

Aetiology

Pathophysiology

Symptomatology

Precipitants

Medications

Outcome

Attitudes

Effect on children

Effect on family

Satisfaction with doctor

Use of alternative medicine

Medications
Frequency of correct answers (mean \%)

Participant group

Comparison group

$\begin{array}{rl}74 \cdot 7 & 55 \cdot 7^{\star} \\ 42 \cdot 3 & 44 \cdot 9 \\ 54 \cdot 7 & 50 \cdot 9 \\ 76 \cdot 7 & 77 \cdot 7 \\ 57 \cdot 4 & 52 \cdot 7 \\ 41 \cdot 8 & 46 \cdot 7 \\ & \\ 44 \cdot 2 & 26 \cdot 6^{\star} \\ 57 \cdot 6 & 52 \cdot 0 \\ 95 \cdot 3 & 78 \cdot 2^{\star} \\ 5 \cdot 8 & 36 \cdot 3^{\star} \\ 15 \cdot 8 & 35 \cdot 5^{\star}\end{array}$

^Statistically significant difference. 
perception of their roles and motivations $(1,3)$. If research subjects are regarded as altruistic heroes or giftgivers, then they would not expect compensation and there is no obligation on the part of society to compensate them, although it may wish to do so as a gesture of appreciation. If research subjects are regarded as opportunists who volunteer to gain access to better medical supervision and care, as in the case of some parents who volunteered their children for an asthma drug trial (6), or as in the case of some AIDS patients, to gain access to potentially curative experimental drugs, then there may be no clear moral obligation for compensation. If research subjects are regarded as willing contractors in a business arrangement, then there is no case for compensation, but it is unlikely that research subjects really understand all the risks involved, nor is the informed consent process completely foolproof (18). Finally, if research subjects are regarded as victims, then they do have a strong moral entitlement to compensation. Hence, there may be a small degree of 'victimisation' in even well-conducted clinical trials, because the informed consent process acts as a social filter to select for inclusion 'these who do not understand, those too frightened to refuse, those who are socially disadvantaged' $(18,19)$. Our own study of parents who volunteered their children for clinical research confirmed that volunteering parents were socially disadvantaged, emotionally vulnerable and psychologically predisposed to volunteering $(6,7)$. In reality, there is a little bit of altruistic hero, giftgiver, opportunist, willing contractor and victim in all research subjects, and it is indeed the current consensus $(1,3)$ that it would be not only uncharitable but also unjust to deny compensation, and by extension good medical aftercare, to these individuals.

\section{Continuing supplies}

The issue of aftercare for participants in clinical research was examined in the context of an asthma drug trial in children in terms of its practical limitations. Because of universal health cover in Australia, the long term medical care of these children including their need for hospitalisation did not present itself as a relevant issue. More relevant was the responsibility of providing the children with continuing supplies of the medication used in the clinical trial for as long as it is needed, but it was considered too financially burdensome by our commercial sponsor, so a compromise was reached to provide it free-of-charge until it becomes licensed and government-subsidised under the Pharmaceutical Benefits Scheme. As it turned out, there was no need to invoke this provision because the drug (ketotifen) was shown to be ineffective in the children concerned (5). A third issue was whether the parents would have gained enough knowledge from the clinical trial to manage their children's asthma better. The data showed that although their under- standing of the aetiology of asthma was better than the comparison group, their overall level of knowledge was quite poor and no better than the comparison group. Attitudes are important predeterminants of behaviour, and in this regard, they were more negative about their children's asthma, more compliant with medications and more trusting of orthodox medicine than the comparison group. These findings indicate that the participating parents would benefit from enrolment in an asthma education programme. As it turned out, we were able to provide the children and parents in our study with continuing care and the benefits of an asthma education programme because of special funding from the Australian Department of Health, Housing and Human Services (20).

While the practical issues of aftercare for our particular group of research subjects and their parents appear to be amenable to a problem-solving approach, our particular set of circumstances may not apply to other types of diseases or health care systems. In countries without free universal health care, the costs of medical and hospital care may constitute a financial disincentive to clinical trials. For treatment of certain chronic diseases such as enzyme medication for Gaucher's disease or anti-rejection medication for organ transplants, where the cost of such medications can run into tens of thousands of dollars per patient per year, pharmaceutical companies would have to pass on the cost to consumers, leading to even higher prices, although this can be considered an equitable way to compensate research subjects who contributed to the development of the drugs in the first place. But the offer of aftercare to research subjects may provide an inducement to volunteer which under certain conditions, may be considered morally wrong and scientifically unsound.

In conclusion, the issue of aftercare for research subjects is fraught with practical difficulties and ethical complexities. This study, the first of its kind to explore this neglected area of clinical ethics, may provide a stimulus for the wider discussion of the ethics of post-trial practices.

\section{Acknowledgements}

This work was supported in part by a grant from the Mayne Bequest Fund, University of Queensland and the Pediatrics Book Fund, Mater Childrens Hospital.

$S C$ Harth, RN, is Senior Research Associate in the Department of Child Health, University of Queensland, Mater Childrens Hospital, South Brisbane, Australia. $Y H$ Thong, $M D, D S c, F R A C P$, is Professor of Child Health in the same department.

\section{References}

(1) Mariner W K. Compensation for research injuries. In: Mastrioianni A C, Faden R, Federman D, eds. 
Women and health research: ethical and legal issues of including women in clinical studies. Washington, DC: National Academy Press, 1994: 113-125.

(2) World Health Organization and Council for International Organisations of Medical Sciences. Proposed international guidelines for biomedical research involving human subjects. Geneva, Switzerland: CIOMS, 1982.

(3) Kolberg R. RAC asks, who should pay for research injuries. Fournal of NIH research 1993; 5: 36-38.

(4) European and Nordic regulations and guidelines for good clinical practice. Austin, Texas: Pharmaco LSR, 1990.

(5) van Asperen P P, McKay K O, Mellis C M, et al. A multicentre randomised placebo-controlled doubleblind study on the efficacy of ketotifen in infants with chronic cough and wheeze. Fournal of paediatrics and child health. 1992; 28: 442-446.

(6) Harth S C, Thong Y H. Sociodemographic and motivational characteristics of parents who volunteer their children for clinical research: a controlled study. British medical journal 1990; 300: 1372-1375.

(7) Harth S C, Johnstone R, Thong Y H. The psychological profile of parents who volunteer their children for clinical research: a controlled study. Fournal of medical ethics 1992; 18: 86-93.

(8) Harth S C, Thong Y H. Parental perceptions and attitudes about informed consent in clinical research involving children. Social science and medicine (in press).

(9) Barnes P J, ed. Asthma. British medical bulletin 1992; 48, part 1: 1-25.

(10) Stempel D A, Szelfler S J, eds. Asthma. Pediatric clinics of North America 1992; 39: 1185-1414.

(11) Howell J H, Flaim T, Lung C L. Patient education. Pediatric clinics of North America 1992; 39: 1343-1361.
(12) Clark N M, Feldman C H, Evans D. The impact of health education on frequency and cost of health care use by low income children with asthma. fournal of allergy and clinical immunology 1986; 78: 108-115.

(13) Spykerboer J E, Donnelly W J, Thong Y H. Parental knowledge and misconceptions about asthma: a controlled study. Social science and medicine 1986; 22: 553-558.

(14) Donnelly J E, Donnelly W J, Thong Y H. Parental perceptions and attitudes toward asthma and its treatment: a controlled study. Social science and medicine 1987; 24: 431-437.

(15) Donnelly J E, Donnelly W J, Thong Y H. Inadequate parental knowledge of asthma medications. Annals of allergy 1989; 62: 337-342.

(16) Donnelly W J, Spykerboer J E, Thong Y H. Are patients who use alternative medicine dissatisfied with orthodox medicine? Medical journal of Australia 1985; 142: 539-541.

(17) SAS Institute Inc. SAS, SAS/STAT. Guide for $\vec{A}$ personal computers. [6th ed]. Cary, North Carolina: i SAS Institute, 1987.

(18) Silverman W A. The myth of informed consent: in 0 daily practice or in clinical trials. Fournal of medical ethics. 1989; 15: 6-11.

(19) Thong Y H, Harth S C. The social filter effect of informed consent in clinical research. Pediatrics 1991; 87: 568-569.

(20) Thong Y H, Harth S C, Masters I B. Development of $\vec{\oplus}$ a home management programme for children with of asthma. Report to the National Health Promotion Programme, Commonwealth Department of Healt Housing and Community Services, Canberra. 199 $1-46$.

\section{News and notes}

\section{East Asian Conference on Bioethics}

The first East Asian Conference on Bioethics will be held from November 3-5 1995, in Beijing, China.

The theme of the conference is bioethics in East Asia and topics will include: The philosophical basis of bioethics in East Asia; Goals of medicine - East and West; Beyond autonomy and human rights; Medical genetics and the human genome project; Reproductive technology and reproductive health - a feminist perspective; The allocation of health resources and the concept of justice, and Environmental ethics and the future of the earth.

The official language of the conference is English.

For further information please contact: Secretariat, EACB '95 $\mathrm{Mr} \mathrm{Gu}$ Dezhang, Chinese Medical Association, 42 Dongsi Xidajie, Beijing 100710, China. Telephone: $(86$ 10) 5134885; 5250394. Fax: (86 10) 5123754. 